CLINICAL STUDY

\title{
Expression of cyclooxygenase-2 in orbital fibroadipose connective tissues of Graves' ophthalmopathy patients
}

\author{
E Berrin Yuksel Konuk, Onur Konuk ${ }^{1}$, Muge Misirlioglu, Adnan Menevse and Mehmet Unal ${ }^{1}$ \\ Departments of Medical Biology and Genetics and ${ }^{1}$ Ophthalmology, Medical Faculty, Gazi University, Ankara, Turkey \\ (Correspondence should be addressed to O Konuk who is now at 8, Cadde 41, Sok no. 3-3 Birlik Mahallesi, O6610 Cankaya, Ankara, Turkey; \\ Email: okonuk@gazi.edu.tr)
}

\begin{abstract}
Objective: The aim of this study is to evaluate the expression of cycloocygenase-2 (COX-2) in orbital fibroadipose connective tissue in Graves' ophthalmopathy (GO) patients, and investigate the associations between COX-2 expression and GO characteristics.

Methods: The orbital fibroadipose connective tissues of 23 cases demonstrating moderate or severe GO, and eight control subjects without any history of thyroid or autoimmune disease were analyzed for COX-2 mRNA expression. Real-time relative quantitative PCR was performed to assess transcripts of COX-2 using the LightCycler. The disease activity was evaluated by the clinical activity score (CAS). The clinical features of GO were evaluated by total eye score (TES) and the cases were divided into two groups; type 1 cases included higher degrees of proptosis with orbital fat volume increase, and type 2 cases included cases with compressive neuropathy and limited extraocular muscle functions.

Results: The mean \pm s.D. disease duration was $5.7 \pm 7.1$ years. The mean \pm s.D. CAS and TES of cases were $1.60 \pm 1.04$ and $7.5 \pm 1.8$ respectively. The mean \pm s.D. expression of COX-2 was $0.023 \pm 0.013$ and $0.010 \pm 0.002$ in GO cases and controls $(P=0.008)$, and $0.015 \pm 0.073$ and $0.029 \pm 0.135$ in type 1 and type 2 cases respectively $(P=0.007)$. COX-2 expression showed a statistically significant positive correlation with TES $(r=0.634, P=0.001)$, and a negative correlation with the disease duration $(r=-0.621, P=0.002)$.

Conclusions: COX-2 is expressed at higher levels in orbital fibroadipose tissues of GO cases. This showed a positive correlation with increasing severity of orbital disease suggesting possible relation with COX-2 expression and orbital inflammation in GO.
\end{abstract}

European Journal of Endocrinology 155 681-685

\section{Introduction}

Graves' ophthalmopathy (GO) is an autoimmune disorder showing characteristic clinical features such as proptosis, eyelid retraction, chemosis, and periorbital edema. Most of these signs can be explained by an increase in the volume of the orbital fibroadipose connective tissue and extraocular muscles in the bony orbit (1). Although the exact pathological pathways of GO are still obscure, the histopathological examination of the orbital tissue reveals inflammatory process via mononuclear cell infiltration predominantly of T-lymphocytes, mast cells, and macrophages with excessive glycosaminoglycan deposition (1-3). Additionally, studies have shown production of cytokines from inflammatory cells, including interleukin (IL) $-1 \alpha$, IL-2, interferon (IFN)- $\gamma$, and tumor necrosis factor (TNF)- $\alpha$ which were regarded as the mediators of inflammation in GO (1-3). Arachidonic acid metabolism is a well-known pathway in the inflammatory process where cyclooxygenase (COX) is a rate-limiting enzyme for the expression of eicosinoids including prostaglandins. Two isoforms of COX have been identified; COX-1 is constitutively expressed in most tissues, whereas COX-2 is induced by various factors, such as growth factors, tumor promoters, and cytokines. Thus, COX-2 is thought to be responsible for prostaglandin production in inflammation (4). Present literature suggests that COX-2 expression may be involved in cell growth, apoptosis, and tumorigenesis in different cell types $(4,5)$. Additionally, in vitro studies have shown induction of COX-2 in orbital fibroblasts of GO cases via proinflammatory cytokines suggesting a possible relationship between COX-2 expression and orbital inflammation in GO (6-8). However, to our knowledge, there is no in situ study demonstrating the expression of COX-2 in orbital fibroadipose tissues of GO patients. The aim of this study is to evaluate the expression of COX-2 in orbital fibroadipose connective tissue and investigate the associations between COX-2 expression and GO characteristics. 


\section{Materials and methods}

Twenty-three consecutive cases (10 male, 13 female) demonstrating moderate or severe GO according to the European group on Graves' orbitopathy (EUGOGO) study were included (9). The disease activity of the cases was evaluated by the clinical activity score (CAS) (10). The clinical features of GO were evaluated with the total eye score (TES) (11) and the cases were divided into two groups; type 1 cases showed higher degrees of proptosis with orbital fat volume increase, and type 2 cases had compressive neuropathy and limited extraocular muscle functions. All cases were euthyroid in both clinical and laboratory examinations (free triiodothyronine and free thyroxine were within normal range, thyroid-stimulating hormone was low or within the normal range) for at least 6 months before surgery. Orbital decompression surgery was performed in all cases and orbital fibroadipose connective tissues were obtained from the infra-temporal area during orbital fat removal. The samples were snap-frozen in dry ice and stored at $-80^{\circ} \mathrm{C}$ for quantitative real-time PCR analysis. Basic clinical data including age, sex, disease duration, history of steroid treatment, and smoking were investigated. Orbital fibroadipose connective tissues of eight patients (four male, four female) without any history of thyroid or autoimmune disease were studied as controls. These samples were obtained during enucleation surgery for management of phthisis bulbi secondary to retinal detachment. The data accumulation was in conformity with the Institutional Review Board, country laws, and the study was in adherence to the tenets of the Declaration of Helsinki. The aim of this study was described and informed consent was received from the patients.

\section{Isolation of RNA and synthesis of cDNA}

Total RNA was extracted from $20 \mathrm{mg}$ frozen tissue samples using High Pure RNA Tissue Kit (Roche Diagnostics) according to the manufacturer's instructions. RNA integrity was electrophoretically verified by ethidium bromide staining and by OD260/OD280 nm absorption ratio of $>1.95$. Total RNA, $1 \mu \mathrm{g}$ was used for cDNA synthesis using first strand cDNA synthesis kit for RT-PCR (avian myeloblastosis virus) (Roche Diagnostics) according to the manufacturer's protocol.

\section{Quantitative analysis of COX-2 mRNA expression}

Real-time quantitative PCR was performed to assess transcripts of COX-2 relative to the housekeeping gene $\beta$-actin using LightCycler instrument (Roche Diagnostics) and results were analyzed by LightCycler software 3.0. Primers and probes were designed using Primer Premier 5 software (Premier Biosoft International, Palo Alto, CA, USA). All primers and probes were designed to cross intron/exon boundaries to avoid amplification of genomic DNA. All PCR products were sequenced to ensure product validity. The upstream and downstream primer sequences for COX-2 gene were 5'-GCTCAAACATGATGTTTGCATTG- $3^{\prime}$ and $5^{\prime}$-GCTGGCCCTCGCTTATGA-3' respectively, and the TaqMan probe selected between the primers was fluorescent-labeled at the $5^{\prime}$ end with 6-carboxyfluorescein (FAM) as the reporter dye and at the $3^{\prime}$ end with 6-carboxytetramethylrhodamine (TAMRA) as the quencher; $5^{\prime}$-FAM-TGCCCAGCACTTCACGCATCAGTT-TAMRA-3' (TibMolBiol, Berlin, Germany; GenBank no. M90100). The $\beta$-actin mRNA was quantified to adjust the amount of mRNA in each sample with $\beta$-actin probe and primer set. The upstream and downstream primer sequences were 5'-TCACCCACACTGTGCCCAT-3' and 5'-TCCTTAATGTCACGCACGATTT- $3^{\prime}$ respectively, and the TaqMan probe was $5^{\prime}$ FAM-ATCCTGCGTCTGGACCTGGCT-TAMRA-3' (TibMolBiol, Berlin, Germany; GenBank no. NM_001101). Each $14 \mu \mathrm{l}$ reaction volume contained $1 \times$ FastStart DNA Master Hybridization Probes Mix (Roche Diagnostics), $4 \mathrm{mM} \mathrm{MgCl} 2,0.5 \mu \mathrm{M}$ of each primer, $0.2 \mu \mathrm{M}$ TaqMan probe, and $2 \mu \mathrm{l} \mathrm{cDNA}$. The cycling parameters were $10 \mathrm{~min}$ at $95^{\circ} \mathrm{C}$ for activating faststart Taq polymerase, 50 cycles of $10 \mathrm{~s}$ at $95^{\circ} \mathrm{C}, 20 \mathrm{~s}$ at $60^{\circ} \mathrm{C}$ for amplification and quantification. In every PCR, the level of the housekeeping gene $\beta$-actin was also quantified with the same PCR conditions described earlier. We used $\beta$-actin as the endogenous internal housekeeping gene that revealed less variability and better reproducibility. Realtime expression values were calculated using the relative standard curve method. Standard curves were generated for each mRNA using tenfold serial dilutions for both the target of interest and the endogenous control ( $\beta$-actin) by measuring the cycle number at which exponential amplification occurred in a dilution series of samples. Values were normalized to the relative amounts of $\beta$-actin mRNA, which were obtained from a similar standard curve. In real-time PCRs, the same initial amounts of target molecules were used, and the cross point $(\mathrm{Cp})$ values $(20.8 \pm 0.02)$ of $\beta$-actin mRNA were constant in all samples. Relative expressions were calculated according to mathematical model based on the PCR efficiencies and the crossing points (12).

\section{Statistical analysis}

Mann-Whitney U-test was used for comparison of COX-2 mRNA expression levels in orbital fibroadipose connective tissues of GO cases versus controls, type 1 versus type 2 cases, and GO cases with or without a smoking habit. The correlation between COX-2 mRNA expression levels and TES and disease duration was calculated by Spearman's test. Statistical significance was set at the 0.05 level for the corrected $P$ value. The 
confidence intervals were calculated so that this percentage is $95 \%$.

\section{Results}

The mean \pm s.D. ages of the study and control groups were $45.0 \pm 11.4$ (range, $24-64$ years) and $41.4 \pm 10.5$ years (range, 29-54 years) respectively $(P>0.05)$. The mean \pm s.D. disease duration was $5.7 \pm 7.1$ years (range, 1-22 years). The mean \pm s.D. TES of cases was $7.5 \pm 1.8$ (range, 3-11). All the cases demonstrated clinical features of inactive orbital disease and the mean \pm s.D. CAS was $1.60 \pm 1.04$ (range, 0-3) at the time of decompression surgery. In the study group, $60.9 \%$ ( 14 out of 23 cases) of the cases had history of systemic steroid treatment, and the mean \pm s.D. period between the discontinuation of steroid therapy and orbital decompression surgery was $10.0 \pm 3.5$ months (range, 6-15 months). None of the patients had history of orbital radiotherapy. All the patients were treated with anti-thyroid drugs, and two had received radioactive iodine for management of hyperthyroidism. Smoking history was positive for $56.5 \%$ (13/23 cases) of the cases, and nine were current smokers.

The mean \pm s.D. expression of COX- $2 / \beta$-actin mRNA was $0.023 \pm 0.013$ (range, 0.005-0.051) and 0.010 \pm 0.002 (range, 0.006-0.015) in GO cases and controls respectively $(P=0.008$; Fig. 1$)$. This value was $0.015 \pm$ 0.073 (range, 0.005-0.028), and 0.029 \pm 0.135 (range, 0.013-0.051) in type 1 and type 2 cases respectively, where type 2 cases showed significantly higher levels of COX-2 expression than type 1 cases $(P=0.007)$. The mean \pm s.D. expression of COX-2/

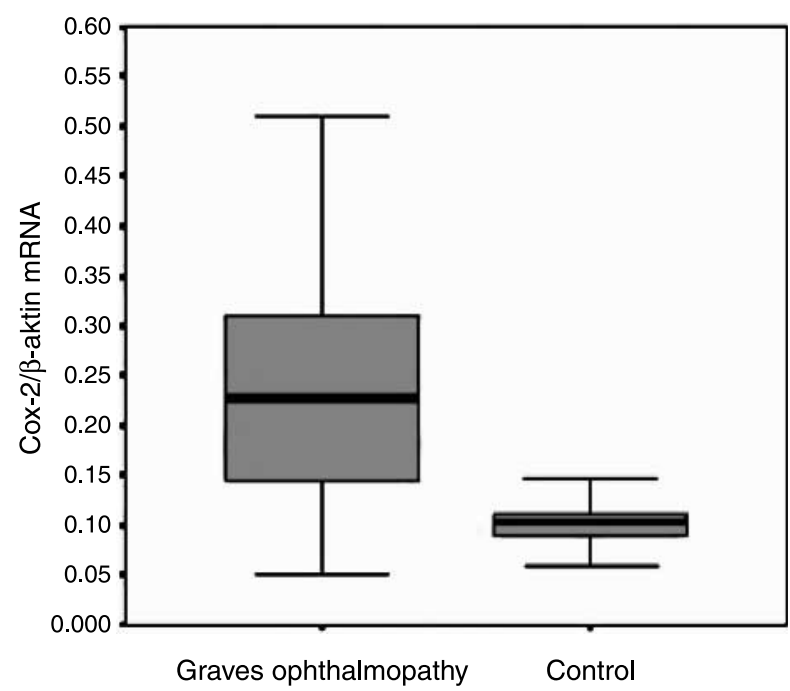

Figure 1 The expression levels of COX2/ $\beta$-actin mRNA in study and control groups. The error bars represent the range of values in each group.

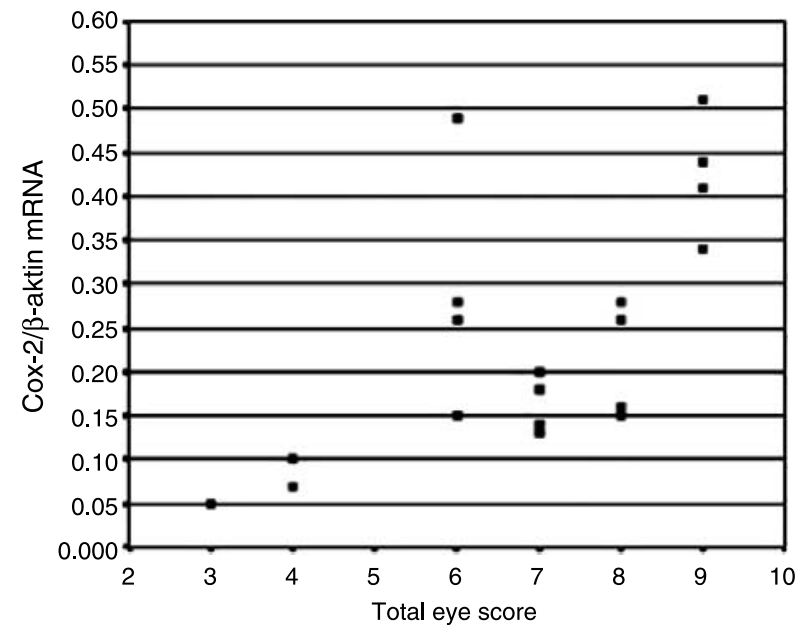

Figure 2 A positive correlation was detected between the levels of COX $2 / \beta$-actin mRNA and total eye score.

$\beta$-actin mRNA was $0.026 \pm 0.014$ (range, 0.0070.051 ) in smokers, and $0.019 \pm 0.011$ (range, 0.005$0.044)$ in non-smokers demonstrating no statistically significant difference $(P=0.24)$. This study showed a statistically significant positive correlation between TES and COX-2 expression $\left(r=0.634, \quad r^{2}=0.401\right.$; $P=0.001)$, and a negative correlation between the disease duration and COX-2 expression $(r=-0.621$, $\left.r^{2}=0.385 ; P=0.002\right)$ (Figs 2 and 3$)$.

\section{Discussion}

The inflammatory cyclooxygenase, COX-2 is usually expressed at extremely low levels under normal basal physiological conditions, but is highly inducible by

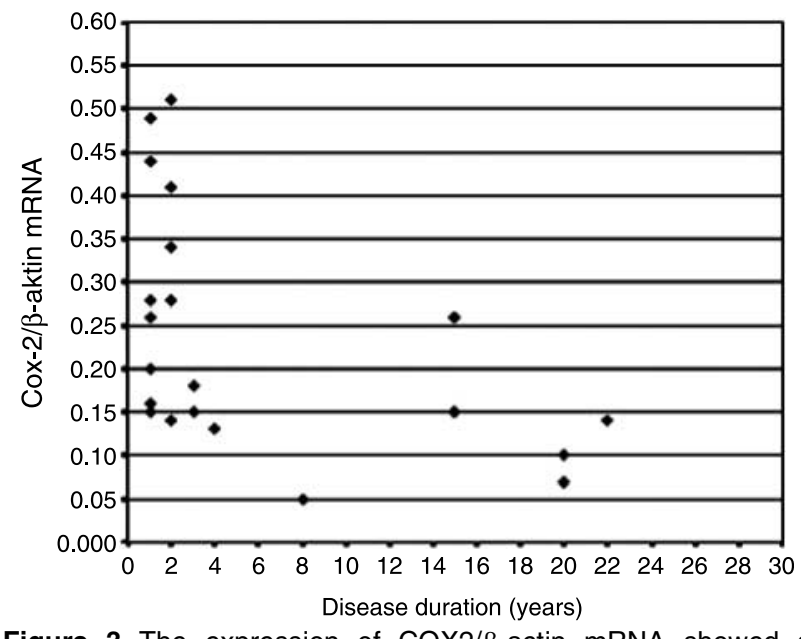

Figure 3 The expression of COX2/ $\beta$-actin mRNA showed a negative correlation with the duration of Graves' ophthalmopathy. 
several factors such as cytokines and mitogens (6-8). The histopathological evidence of orbital inflammation in GO was revealed through demonstrating mononuclear cells, predominately T-cells, with the minority being B-lymphocytes. The cytokines released from infiltrating monocytes were believed to initiate orbital tissue reactivity in $\mathrm{GO}(3,13)$. There are in vitro studies demonstrating the expression of $\mathrm{COX}^{-2}$ in orbital fibroblasts of GO cases. Wang et al. (7) showed that leukoregulin, a T-cell-derived cytokine, can upregulate COX-2 in human fibroblasts without affecting the COX1 levels. Additionally, Han et al. (6) also showed induction of both COX-2 and prostaglandin E2 (PGE2) synthase expression via IL-1 $\beta$ in cultured orbital fibroblasts. In this study, we report that expression of COX-2 in orbital fibroadipose connective tissues of GO cases is higher than the control group, and its expression demonstrates a positive correlation with increasing severity of orbital disease. The clinical course of GO is characterized by an initial active congestive phase, which is followed by an inactive fibrotic phase (14). The management of acute orbital inflammation comprises immunosuppressive treatment most commonly with high dose systemic corticosteroid treatment (15). It has been shown that glucocorticoids can effectively block the synthesis of COX-2 and PGE2 that might explain the clinical benefits with glucocorticoid therapy in GO (1). In clinical practice, the features of acute orbital inflammation usually subside in $1-5$ years. Our study shows that the expression of COX-2 mRNA has a statistically significant negative correlation with disease duration supporting the self-limiting course of orbital inflammation. Kumar and Bahn (13) showed the increased levels of macrophage-derived cytokines in orbital tissues of longstanding GO cases, suggesting the ongoing orbital inflammation at histopathological level in the chronic fibrotic phase of the disease. Our study supports this idea at a molecular level by demonstrating the elevated levels of $\mathrm{COX}-2$ expression in orbital fibroadipose connective tissues of GO cases with inactive orbital disease. However, it should be noticed that both studies used RT-PCR, so the results are limited to RNA expression and every expressed RNA will not be translated into active protein. The management of GO may take a period of time and comprise continuation of anti-inflammatory treatment to suppress the orbital disease. Since long-term corticosteroid treatment is associated with significant morbidity, selective COX-2 inhibitors may be administered alternatively in the maintenance of treatment for orbital inflammation.

To our knowledge, this is the first in situ study demonstrating increased levels of $\mathrm{COX}-2$ expression in orbital fibroadipose connective tissue of GO cases with real-time PCR that gives accurate and reproducible results for quantification of gene expression. In this study, we evaluated the expression of COX-2 in cases with chronic orbital disease and unfortunately could not make a comparison of COX-2 levels between acute and chronic orbital disease. Consequently, the decrease in the expression of COX-2 could not be demonstrated following immunosuppressive treatment. Over half of the patients included in this study had received systemic corticosteroid treatment during the acute phases of their diseases, since acute orbital inflammation usually necessitates antiinflammatory treatment to prevent sight-threatening complications. At this stage, orbital tissue sampling via orbital decompression is not compatible in these patients. Although the corticosteroid treatment in those cases might decrease the expression of COX-2 in orbital tissues, the demonstrated levels in the study group were still statistically higher than the control group. Further studies may demonstrate the association between COX-2 expression and the clinical features of GO, and its relation with anti-inflammatory treatments.

\section{Acknowledgements}

This study was supported by Gazi University Department of Scientific Investigation Grant no. 1/2004-60.

\section{References}

1 Prabhakar BS, Bahn RS \& Smith TJ. Current perspective on the pathogenesis of Graves' disease and ophthalmopathy. Endocrine Reviews 200324 802-835.

2 Ajjan RA \& Weetman AP. New understanding of the role of cytokines in the pathogenesis of Graves' ophthalmopathy. Journal of Endocrinological Investigation 200427 237-245.

3 Smith TJ. Novel aspects of orbital fibroblast pathology. Journal of Endocrinological Investigation 200427 246-253.

4 Smith WL, DeWitt DL \& Garavito RM. Cyclooxygenases: structural, cellular, and molecular biology. Annual Review of Biochemistry 200069 145-182.

5 Dubois RN, Abramson SB, Crofford L, Gupta RA, Simon LS, Van De Putte LB \& Lipsky PE. Cyclooxygenase in biology and disease. FASEB Journal 199812 1063-1073.

6 Han R, Tsui S \& Smith TJ. Up-regulation of prostaglandine E2 synthesis by interleukin $1 \beta$-in human orbital fibroblasts involves coordinate induction of prostaglandine-endoperoxide $H$ synthase- 2 and glutathione dependent prostaglandine E2 synthase expression. Journal of Biological Chemistry 2002277 16355-16364.

7 Wang HS, Cao HJ, Winn VD, Rezanka LJ, Frobert Y, Evans CH, Sciaky D, Young DA \& Smith TJ. Leukoregulin induction of prostaglandine--endoperoxide $\mathrm{H}$ synthase-2 in human orbital fibroblasts. An in vitro model for connective tissue inflammation. Journal of Biological Chemistry $199627122718-22728$.

8 Cao HJ, Wang HS, Zhang Y, Lin HY, Phipps RP \& Smith TJ. Activation of human orbital fibroblasts through CD40 engagement results in a dramatic induction of hyaluranan synthesis and prostaglandineendoperoxide $\mathrm{H}$ synthase-2 expression. Insights into potential pathogenic mechanisms of thyroid-associated ophthalmopathy. Journal of Biological Chemistry 1998273 29615-29625.

9 Prummel MF, Bakker A, Wiersinga WM, Baldeschi L, Mourits MP, Kendall-Taylor P, Perros P, Neoh C, Dickinson AJ, Lazarus JH, Lane CM, Heufelder AE, Kahaly GJ, Pitz S, Orgiazzi J, Hullo A, Pinchera A, Marcocci C, Sartini MS, Rocchi R, Nardi M, Krassas GE \& Halkias A. Multi-center study on the characteristics and 
treatment strategies of patients with Graves' orbitopathy: the first European Group on Graves' orbitopathy experience. European Journal of Endocrinology $2003 \mathbf{1 4 8} 491-495$.

10 Mourits MP, Prummel MF, Wiersinga WM \& Koornneef L. Clinical activity score as a guide in the management of patients with Graves' ophthalmopathy. Clinical Endocrinology $1997479-14$.

11 Prummel MF, Mourits MP, Berghout A, Krenning EP, van der Gaag R, Koornneef L \& Wiersinga WM. Prednisone and cylcosporine in the treatment of severe Graves' ophthalmopathy. New England Journal of Medicine 1989321 1353-1359.

12 Pfaffl MW. A new mathematical model for relative quantification in real-time RT-PCR. Nucleic Acids Research 200129 2002-2007.
13 Kumar S \& Bahn RS. Relative overexpression of macrophagederived cytokines in orbital adipose tissue from patients with Graves' ophthalmopathy. Journal of Clinical Endocrinology and Metabolism $2003 \mathbf{8 8} 4246-4250$.

14 Rundle FF. Eye signs of Graves' disease. In The Thyroid, pp 171-197. EdsR Pitt-Rivers \& WR Trotter, Washington, DC: Butterworths and Co, 1964.

15 Kazim M, Trokel S \& Moore S. Treatment of acute Graves' orbitopathy. Ophthalmology 199198 1443-1448.

Received 12 June 2006

Accepted 29 August 2006 